\title{
Louse-borne relapsing fever (Borrelia recurrentis) in an Eritrean refugee arriving in Switzerland, August 2015
}

\author{
D Goldenberger (daniel.goldenberger@usb.ch) ${ }^{1,2}$, G J Claas ${ }^{2,3}$, C Bloch-Infanger 3 , T Breidthardt ${ }^{4}$, B Suter ${ }^{5}$, M Martínez $^{5}$, A

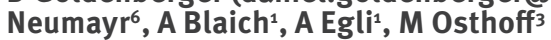 \\ 1. Division of Clinical Microbiology, University Hospital Basel, Basel, Switzerland \\ 2. These authors contributed equally to this work \\ 3. Division of Infectious Diseases and Hospital Epidemiology, University Hospital Basel, Basel, Switzerland \\ 4. Division of Internal Medicine, University Hospital Basel, Basel, Switzerland \\ 5. Division of Diagnostic Haematology, University Hospital Basel, Basel, Switzerland \\ 6. Swiss Tropical and Public Health Institute, Basel, Switzerland
}

We report an imported case of louse-borne relapsing fever in a young adult Eritrean refugee who presented with fever shortly after arriving in Switzerland. Analysis of blood smears revealed spirochetes identified as Borrelia recurrentis by $16 \mathrm{~S}$ rRNA gene sequencing. We believe that louse-borne relapsing fever may be seen more frequently in Europe as a consequence of a recent increase in refugees from East Africa travelling to Europe under poor hygienic conditions in confined spaces.

Here we communicate a case of louse-borne relapsing fever (LBRF) in an Eritrean refugee after arrival in Switzerland in August 2015. Borrelia recurrentis, the causative agent of LBRF, was identified by $16 \mathrm{~S}$ rRNA gene sequencing. In addition to diagnostic and therapeutic aspects, we discuss the epidemiology of this potentially re-emerging and serious disease in the context of a recent increase in refugees from East Africa travelling to Europe.

\section{Case description}

In August 2015, a refugee from Eritrea in their late $20 \mathrm{~s}$ presented to our emergency department with fever for two days, nausea, headache, dysuria and bilateral flank pain. After leaving Eritrea about two months earlier with stopovers in Sudan (two weeks) and Libya (three weeks), the patient arrived in Italy ca 12 days before presenting to our hospital (Figure 1). On their way through Sudan, the patient had experienced a similar episode of dysuria and flank pain without fever that was not treated. Others travelling with them had febrile illnesses that were diagnosed as malaria. All of the patient's clothes were exchanged once in Libya and a second time after arrival in Italy.

On presentation, the patient was afebrile and blood pressure and heart rate were within normal limits.
Physical examination was significant for suprapubic and right flank tenderness, whereas skin examination was unremarkable. In particular, lice were not detected on the patient's clothes. Routine blood tests demonstrated mild microcytic anaemia (haemoglobin 101 $\mathrm{g} / \mathrm{L}$; norm: 140-180), thrombocytopenia (108 x 109/L; norm: 150-450) and elevated C-reactive protein (CRP: $108 \mathrm{mg} / \mathrm{L}$; norm: $(10)$. Urine analysis revealed mild pyuria ( $266 / \mu \mathrm{L}$; norm $0-40)$ and abundant squamous epithelial cells ( $45 / \mu \mathrm{L}$; norm o-9). Blood smears demonstrated a large number of extracellular spirochetes (Figure 2). Blood cultures remained negative and only bifidobacteria grew in urine culture. Serological screening tests for human immunodeficiency virus (HIV), syphilis and Lyme disease were negative.

The patient was initially treated with doxycycline $100 \mathrm{mg}$ twice per day over two days and ceftriaxone $2 \mathrm{~g}$ per day to cover Borrelia-associated relapsing fever and suspected pyelonephritis. We did not observe a Jarisch-Herxheimer reaction [1]. They remained afebrile throughout the admission, and their pain and dysuria settled immediately after initiation of antibiotic treatment. Ceftriaxone was stopped after five days of treatment and the patient was discharged for outpatient follow-up.

\section{Investigation of the disease-causing agent}

Subsequently, analyses were performed to further characterise the causative agent of the patients' relapsing fever syndrome. The detection and identification of $B$. recurrentis was performed with broad-range bacterial PCR followed by partial sequencing of the 16S rRNA gene applied to two EDTA blood specimens drawn two hours (before treatment, microscopy-positive) and 18 hours (after the first dose of ceftriaxone, microscopynegative) after presentation to our hospital [2]. PCR 


\section{FIGURE 1}

Travel route from Eritrea to Europe, louse-borne relapsing fever case, Switzerland, August 2015

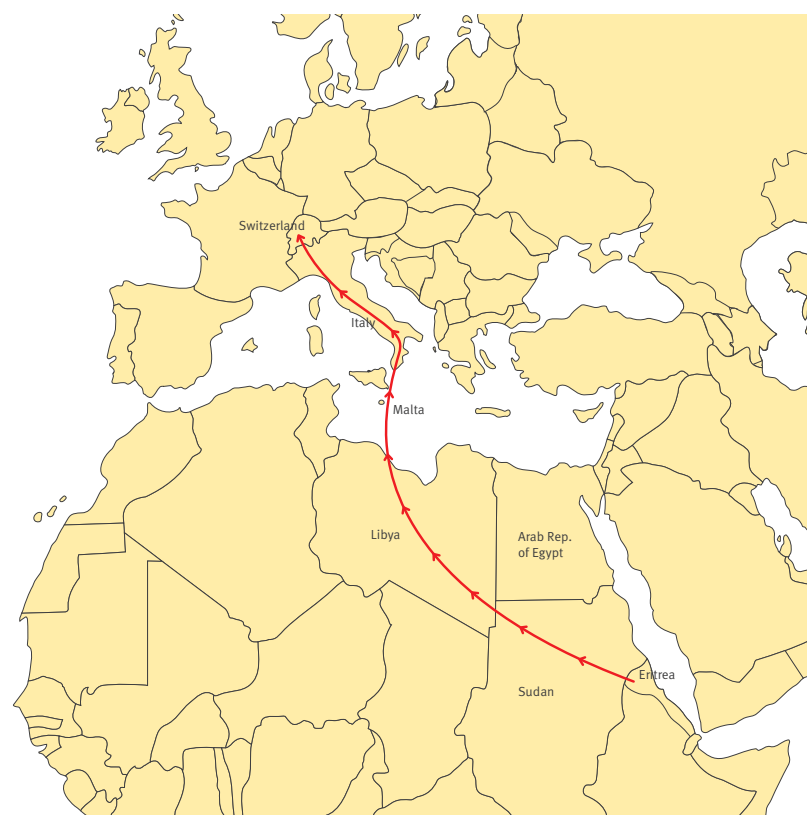

\section{FIGURE 2}

Microscopic detection of spirochetes in blood, louse-borne relapsing fever case, Switzerland, August 2015

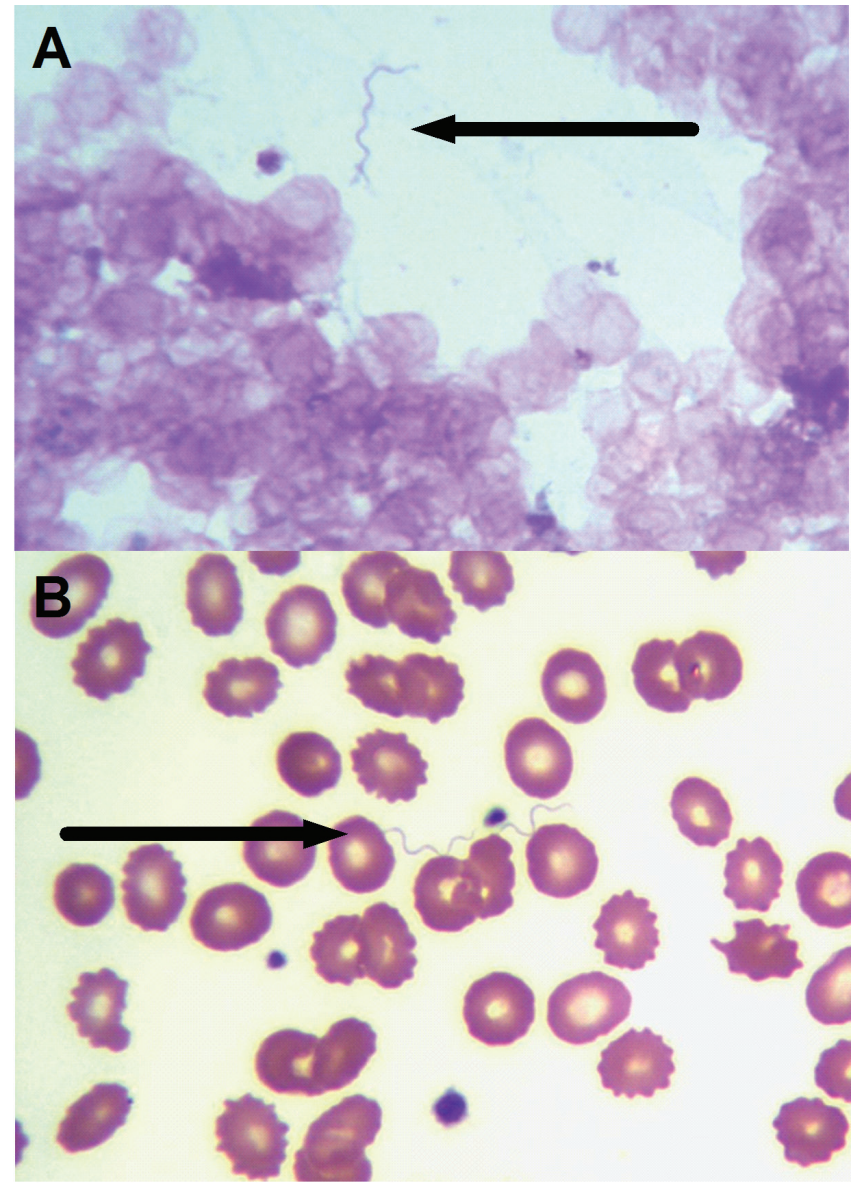

Panel A: Giemsa pH 7.2, stained thick film, 1,000-fold magnification.

Panel B: May-Grünwald Giemsa (MGG)-stained blood smear, 1,00ofold magnification. was positive only on the first sample (100\% identity with the $B$. recurrentis reference strain $A 1)$.

In a very recent LBRF patient, we additionally analysed the entire $16 \mathrm{~S}$ rRNA gene, which yielded a 1,475 bp sequence (GenBank accession number: KT221542). Nucleotide sequence database analysis using the Basic Local Alignment Search Tool (BLAST, National Library of Medicine) showed $100 \%$ identity to the $B$. recurrentis reference strain $\mathrm{A}_{1}$ [3].

\section{Background}

LBRF once was a major worldwide endemic disease causing significant mortality in untreated patients (10-70\%) [4-6]. The incubation period is usually short (four to eight days with a range of two to 15 days). In contrast to other Borrelia-associated relapsing fever syndromes, LBRF is considered a disease specific to the human host caused by $B$. recurrentis and transmitted by the human body louse Pediculus humanus humanus as the vector. In parallel with the markedly reduced incidence of body louse infestations after the 1940s, LBRF cases declined significantly worldwide with the exception of East African countries, in particular Ethiopia, where LBRF remains a common cause of hospital admission and death [7]. Interestingly, cases of LBRF have not recently been reported outside of Africa, including in refugees from affected countries, which may be indicative of a true decline in incidence or a lack of outbreaks in affected countries [8] rather than of difficulties in diagnosis, although microscopy of blood films has a low sensitivity and cannot differentiate between Borrelia species [9]. Hence, duration of treatment for Borrelia-associated relapsing fever syndromes, which differs according to the species, is usually determined based on geographical location and the respective predominant vector. Whereas single-dose procaine penicillin, tetracycline $(500 \mathrm{mg})$ or doxycycline $(200 \mathrm{mg})$ are effective treatment regimens for LBRF, treatment duration with doxycycline, penicillin $\mathrm{G}$ or ceftriaxone is much longer (10 to 14 days) in the case of TBRF.

\section{Discussion}

The current arrival of refugees from East Africa to Europe poses challenges for clinicians in European countries as they may be faced with tropical diseases including malaria [10] and diseases nowadays rarely diagnosed in Europe; for example, cases of cutaneous diphtheria have recently been diagnosed in refugees from East Africa at our institution (data not shown). In addition, some of these diseases have the potential to cause small outbreaks in refugee camps $[11,12]$. We present a case of LBRF imported into Europe in the context of the ongoing migration of refugees from Africa.

Taking into account the short incubation period and the patient's travel dates with a possible episode while residing in Sudan, infection with LBRF probably occurred in Eritrea, Sudan or Libya. Apart from Ethiopia, LBRF has previously been reported from Eritrea and 
Sudan [6], the former being the predominant country of origin and the latter a common transit country of many refugees arriving in Europe [13]. Given the poor hygienic conditions and crowding on the way to Europe that might facilitate spread of $B$. recurrentis via body lice, we expect that cases of LBRF will be diagnosed more frequently in Europe. We can only speculate that despite a sustained high prevalence in neighbouring Ethiopia [7], LBRF is not a common disease in Eritrea or Sudan. However, this may change with the continuing increase in refugees from this area, in particular if Ethiopian foci of LBRF infection reach neighbouring countries such as Sudan [14] or if migrants from LBRFendemic Ethiopia live or travel together with other refugees in confined spaces. Of note, two similar cases have just recently been diagnosed in Eritrean refugees arriving in the Netherlands [19].

While the human body louse has been considered the principal vector of $L B R F, B$. recurrentis DNA was recently detected in head lice (Pediculus humanus capitis) [15], although it remains to be determined whether $B$. recurrentis can be transmitted via head lice from person to person. In any case, we consider screening arriving refugees for lice useful in order to prevent spreading of louse-borne diseases in refugee camps. Given that our case's clothes had been exchanged twice before arrival in Switzerland and the fact that lice were not detected in their present clothes, neither formal contact tracing nor additional screening of refugees living in the same asylum seeker camp for lice or preventive delousing were conducted. Comprehensive source tracing is difficult, in our opinion, as it is impossible to locate and investigate all refugees that have previously travelled with a case in crowded conditions.

Patients with LBRF usually present with non-specific symptoms such as high fever, headache or pain in other parts of the body [16]. Hence, presentation of LBRF may resemble many other serious infections such as malaria, viral haemorrhagic fever, leptospirosis, typhus, TBRF, meningococcal meningitis or typhoid fever [17]. In addition, co-infection with malaria is common [16], although not detected in our patient. Most patients with LBRF are diagnosed using microscopy. This method lacks interspecies differentiation of Borrelia species causing relapsing fever syndromes, which is important for determining treatment duration (see below). Molecular diagnostic tests such as multiplex PCR or $16 \mathrm{~S}$ rRNA gene analysis or are not universally available but can aid in the diagnosis of LBRF [18]. Our case demonstrates that the detection and identification of the aetiological agent can be performed by 16S rRNA gene analysis directly from blood samples. Physicians should consider LBRF as differential diagnosis in refugees from East Africa presenting with fever of unknown origin, as mortality in untreated patients is high. Single-dose procaine penicillin, tetracycline (500 $\mathrm{mg}$ ) or doxycycline $(200 \mathrm{mg})$ are effective treatments for LBRF; the evidence for the superiority of tetracyclines is weak with regards to the risk of relapse and time to defervescence [1]. On the other hand, physicians should be aware of higher rates of the JarischHerxheimer reaction with the use of tetracyclines [1].

\section{Conclusion}

Physicians in countries currently hosting Eritrean refugees need to consider LBRF in febrile migrants in addition to more common diseases like malaria.

\section{Acknowledgements}

We thank Leena Baumann (Department of Environmental Sciences, University of Basel) for providing appropriate map and Dr. Reno Frei (Head of Clinical Microbiology, University Hospital Basel) for critical review of the manuscript. We acknowledge Jacqueline Metaxas, Elisabeth Schultheiss, Ralf Beyrau and Fabrizio Dutly for excellent technical assistance. We thank Dr. med. Jürg Kremo, Basel for clinical and administrative support.

\section{Conflict of interest}

None declared.

\section{Authors' contributions}

Wrote the manuscript: DG, GJC, AE, MO; performed laboratory investigations: $D G, M M, A B, B S$; revised manuscript: $D G, G J C, C B, T B, M M, A N, A B, A E, M O$; managed the patient: $\mathrm{GJC}, \mathrm{CB}, \mathrm{TB}, \mathrm{MO}$.

\section{References}

1. Guerrier G, Doherty T. Comparison of antibiotic regimens for treating louse-borne relapsing fever: a meta-analysis. Trans R Soc Trop Med Hyg. 2011;105(9):483-90. http://dx.doi. org/10.1016/j.trstmh.2011.04.004 PMID:21803390

2. Hinić V, Aittakorpi A, Suter S, Turan S, Schultheiss E, Frei R, et al. Evaluation of the novel microarray-based Prove-it ${ }^{T M}$ Bone\&Joint assay for direct detection of pathogens from normally sterile body sites in comparison with culture and broad-range bacterial PCR. J Microbiol Methods. 2014;107:3840. http://dx.doi.org/10.1016/j.mimet.2014.08.004 PMID:25194235

3. Lescot M, Audic S, Robert C, Nguyen TT, Blanc G, Cutler SJ, et al. The genome of Borrelia recurrentis, the agent of deadly louse-borne relapsing fever, is a degraded subset of tick-borne Borrelia duttonii. PLoS Genet. 2008;4(9):e1000185. http:// dx.doi.org/10.1371/journal.pgen.1000185 PMID:18787695

4. Cutler SJ. Relapsing fever--a forgotten disease revealed. J Appl Microbiol. 2010;108(4):1115-22. http://dx.doi.org/10.1111/ j.1365-2672.2009.04598.x PMID:19886891

5. Bryceson AD, Parry EH, Perine PL, Warrell DA, Vukotich D, Leithead CS. Louse-borne relapsing fever. Q J Med. 1970;39(153):129-70. PMID:4913454

6. Raoult D, Roux V. The body louse as a vector of reemerging human diseases. Clin Infect Dis. 1999;29(4):888-911. http:// dx.doi.org/10.1086/520454 PMID:10589908

7. Yimer M, Mulu W, Ayalew W, Abera B. Louse-borne relapsing fever profile at Felegehiwot referral hospital, Bahir Dar city, Ethiopia: a retrospective study. BMC Res Notes. 2014;7(1):250. http://dx.doi.org/10.1186/1756-0500-7-250 PMID:24742342

8. Ramos JM, Malmierca E, Reyes F, Tesfamariam A. Results of a 10-year survey of louse-borne relapsing fever in southern Ethiopia: a decline in endemicity. Ann Trop Med Parasitol. 2008;102(5):467-9. http://dx.doi. org/10.1179/136485908X300887 PMID:18577339

9. Cutler SJ, Abdissa A, Trape JF. New concepts for the old challenge of African relapsing fever borreliosis. Clin Microbiol Infect. 2009;15(5):400-6. http://dx.doi.org/10.1111/j.14690691.2009.02819.x PMID:19489922 
10. Sonden K, Castro E, Törnnberg L, Stenstrom C, Tegnell A, Farnert A. High incidence of Plasmodium vivax malaria in newly arrived Eritrean refugees in Sweden since May 2014. Euro Surveill. 2014;19(35):20890. http://dx.doi.org/10.2807/15607917.ES2014.19.35.20890 PMID:25210980

11. Santaniello-Newton A, Hunter PR. Management of an outbreak of meningococcal meningitis in a Sudanese refugee camp in Northern Uganda. Epidemiol Infect. 2000;124(1):75-81. http:// dx.doi.org/10.1017/S0950268899003398 PMID:10722133

12. Brown V, Larouze B, Desve G, Rousset JJ, Thibon M, Fourrier $A$, et al. Clinical presentation of louse-borne relapsing fever among Ethiopian refugees in northern Somalia. Ann Trop Med Parasitol. 1988;82(5):499-502. PMID:3257078

13. United Nations High Commissioner for Refugees (UNCR). Sharp increase in number of Eritrean refugees and asylum-seekers in Europe, Ethiopia and Sudan. Geneva: UNCR; Nov 2014. Available from: http://www.unhcr.org/5465fea1381.html

14. de Jong J, Wilkinson RJ, Schaeffers P, Sondorp HE, Davidson RN. Louse-borne relapsing fever in southern Sudan. Trans R Soc Trop Med Hyg. 1995;89(6):621. http://dx.doi. org/10.1016/0035-9203(95)90414-X PMID:8594674

15. Boutellis A, Mediannikov O, Bilcha KD, Ali J, Campelo D, Barker SC, et al. Borrelia recurrentis in head lice, Ethiopia. Emerg Infect Dis. 2013;19(5):796-8. http://dx.doi.org/10.3201/ eid1905.121480 PMID:23648147

16. Ramos JM, Malmierca E, Reyes F, Wolde W, Galata A, Tesfamariam A, et al. Characteristics of louse-borne relapsing fever in Ethiopian children and adults. Ann Trop Med Parasitol. 2004;98(2):191-6. http://dx.doi. org/10.1179/000349804225003136 PMID:15035729

17. European Centre for Disease Control and Prevention (ECDC). Louse-borne relapsing fever; Factsheet for health professionals. Stockholm: ECDC; [Accessed Jul 2015]. Available from: http://ecdc.europa.eu/en/healthtopics/emerging and vector-borne_diseases/vector-borne_diseases/louse-bornerelapsing-fever/Pages/Factsheet-for-health-professionals.aspx

18. Elbir H, Henry M, Diatta G, Mediannikov O, Sokhna C, Tall A, et al. Multiplex real-time PCR diagnostic of relapsing fevers in Africa. PLoS Negl Trop Dis. 2013;7(1):e2042. http://dx.doi. org/10.1371/journal.pntd.0002042 PMID:23390560

19. Wilting KR, Stienstra Y, Sinha B, Braks M, Cornish D, Grundmann H. Louse-borne relapsing fever (Borrelia recurrentis) in asylum seekers from Eritrea, the Netherlands, July 2015. Euro Surveill. 2015;20(30):pii=21196. 